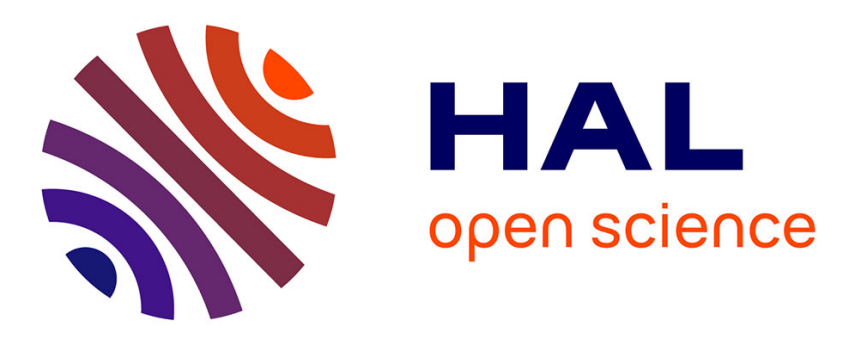

\title{
Multi-hop, multi-route power minimisation in ad hoc network
}

Pierre Gérold, Thi-Thuy-Ngoc Pham, Florence Alberge, Pierre Duhamel

\section{To cite this version:}

Pierre Gérold, Thi-Thuy-Ngoc Pham, Florence Alberge, Pierre Duhamel. Multi-hop, multi-route power minimisation in ad hoc network. ICASSP 2012 - 37th IEEE International Conference on Acoustics, Speech and Signal Processing, Mar 2012, Kyoto, Japan. hal-01849646

\section{HAL Id: hal-01849646 \\ https://hal.science/hal-01849646}

Submitted on 26 Jul 2018

HAL is a multi-disciplinary open access archive for the deposit and dissemination of scientific research documents, whether they are published or not. The documents may come from teaching and research institutions in France or abroad, or from public or private research centers.
L'archive ouverte pluridisciplinaire HAL, est destinée au dépôt et à la diffusion de documents scientifiques de niveau recherche, publiés ou non, émanant des établissements d'enseignement et de recherche français ou étrangers, des laboratoires publics ou privés. 
Pierre Gerold, Thi-Thuy-Ngoc Pham , Florence Alberge, Pierre Duhamel e-mail:\{pierre.gerold,alberge, pierre.duhamel\}@llss.supelec.fr,phamthithuyngoc@gmail.com

\section{Problem}

This paper studies the problem of finding the optimal route of a stream between the transmitter and the receiver in an ad hoc network while minimizing the total power consumption. The main step of this work is modeling the transmissions as a graph, deduce the associated optimization problem and find a way to solve it.

Compared to previous approaches, we introduce more flexibility by allowing the stream to be split between several intermediate destinations, and we do not use the specific approximations (mainly high SNR) required to make the problem convex.

We illustrate our work using the following example where transmitions are splitted into two different channel to model the equivalent of downlink and uplink at each node. We call this graph $\zeta$

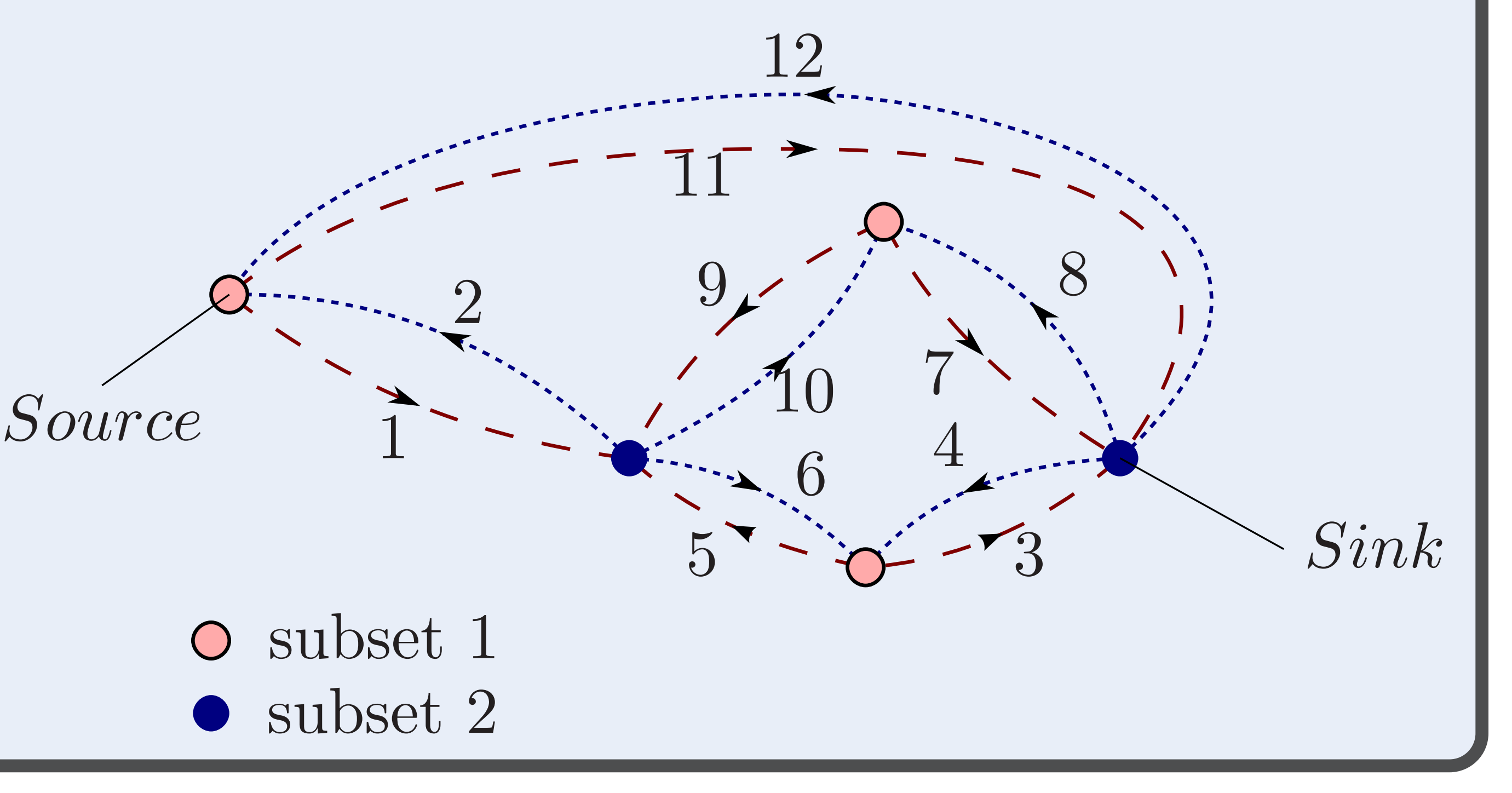

\section{Model}

As we attent to manage multiuser interference, we use a quite rough multiuser transmission sheme: a BCIM (Bit Interleaved Coded Modualtion). So the node $k$ receives at each time:

$$
Y_{k}=\sqrt{G_{k k}} X_{k}+\underbrace{\left(\sum_{\substack{i \in \zeta \\ i \neq k}} \sqrt{G_{i k}} X_{i}+N\right)}_{\text {Supposed Gaussian noise }}
$$

Where $G_{k k}$ is the power gain of the link $k$, and $G_{i k}$ the power of the link $i$ interfering on $k$. So we derive a capacity from the well known Shannon capacity:

$$
R_{k}^{\zeta} \leq \log \left(1+\frac{P_{k} \cdot G_{k}}{\sigma^{2}+\sum_{\substack{i \in \zeta \\ i \neq k}} \Theta_{i, k} \cdot P_{i} \cdot G_{i, k}}\right)
$$

\section{The routing constraint}

The data flow model we use to express the routing constraint could be expressed.

$$
\mathbf{E} . \mathbf{R}^{\mathcal{E}}=\mathbf{S}
$$

Where $\mathbf{E}$ is the incidence matrix of the graph and the source sink vector. This formualtion lead to express $\mathbf{R}^{\mathcal{E}}$ as a function of less but free variables.

$$
\mathbf{R}^{\mathcal{E}}=\mathbf{M} \cdot \mathbf{R}_{c T}^{\mathcal{E}}
$$

But this formulation have to be done in a slightly different graph: with the network flow graph, rate could be negative. So we route in the following graph noted $\epsilon$ and then map into the $\zeta$ graph.

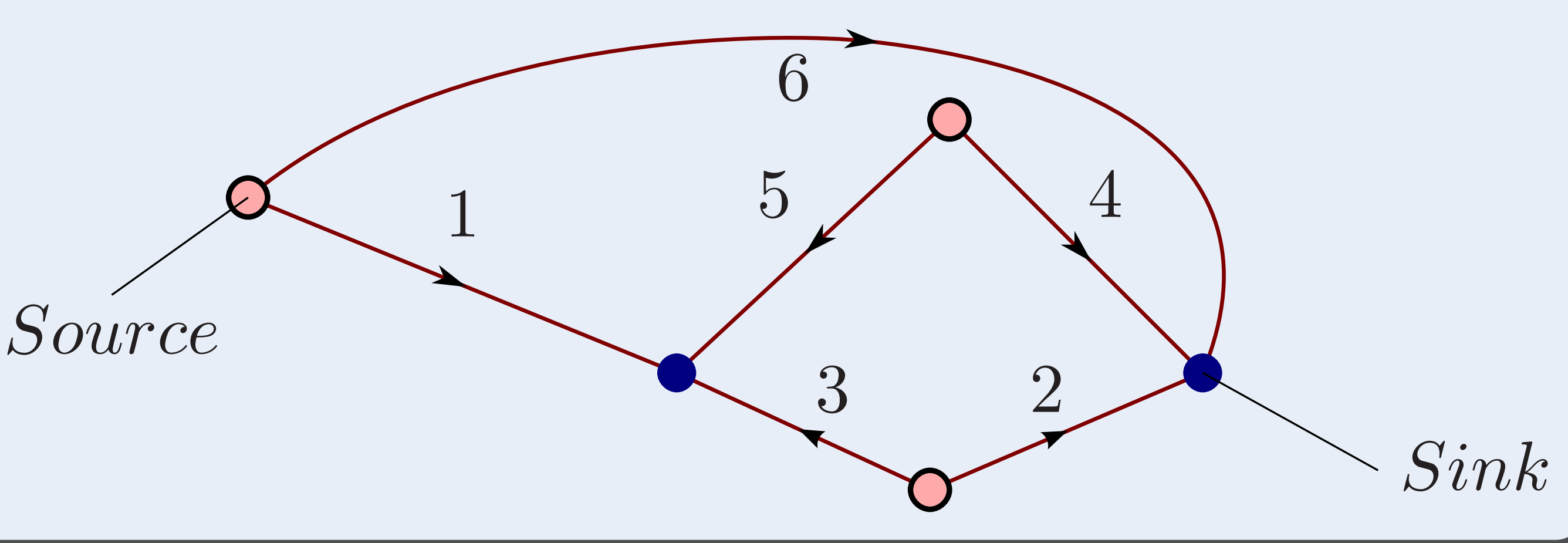

The optimization problem

The transmission at Shannon capacity could be written:

$$
\mathbf{A}\left(\mathbf{R}^{\zeta}\right) \cdot \mathbf{P}=\mathbf{B}\left(\mathbf{R}^{\zeta}\right)
$$

with $\mathbf{A}=$

$$
\begin{aligned}
& {\left[\begin{array}{ccc}
G_{1,1} & -\left(2^{R_{1}^{\zeta}}-1\right) G_{1,2} & \cdots \\
-\left(2^{R_{2}^{\zeta}}-1\right) G_{2,1} & G_{2,2} & \cdots \\
-\left(2^{R_{3}^{\zeta}}-1\right) G_{3,1} & -\left(2^{R_{3}^{\zeta}}-1\right) G_{3,2} & \cdots \\
\vdots & \vdots & \ddots
\end{array}\right]} \\
& \mathbf{B}=\left[\begin{array}{c}
\left(2^{R_{1}^{\zeta}}-1\right) \cdot \sigma^{2} \\
\left(2^{R_{2}^{\zeta}}-1\right) \cdot \sigma^{2} \\
\vdots
\end{array}\right]
\end{aligned}
$$

Then, assuming $\mathbf{A}$ is non-singular, we could formulate our problem on a matrix formulation:

$$
\min _{\mathbf{R}_{c T}^{\mathcal{E}} \in \mathbb{R}^{L-N-1}}\left\|\mathbf{P}\left(\mathbf{A}^{-1} \mathbf{B}\right)\left(\mathbf{R}_{c T}^{\mathcal{E}}\right)\right\|_{1}
$$

\section{Simulation}

The simulation corresponds to our example. We plot the criterion $\left\|\mathbf{P}\left(\mathbf{A}^{-1} \mathbf{B}\right)\left(\mathbf{R}_{c T}^{\mathcal{E}}\right)\right\|_{1}$ as a function of the relative rate of the co-tree (link 5 and link 6 on the $\epsilon$ graph ). Then, we plot the convergence of the algorithm to the global minimum on $(0,0)$.
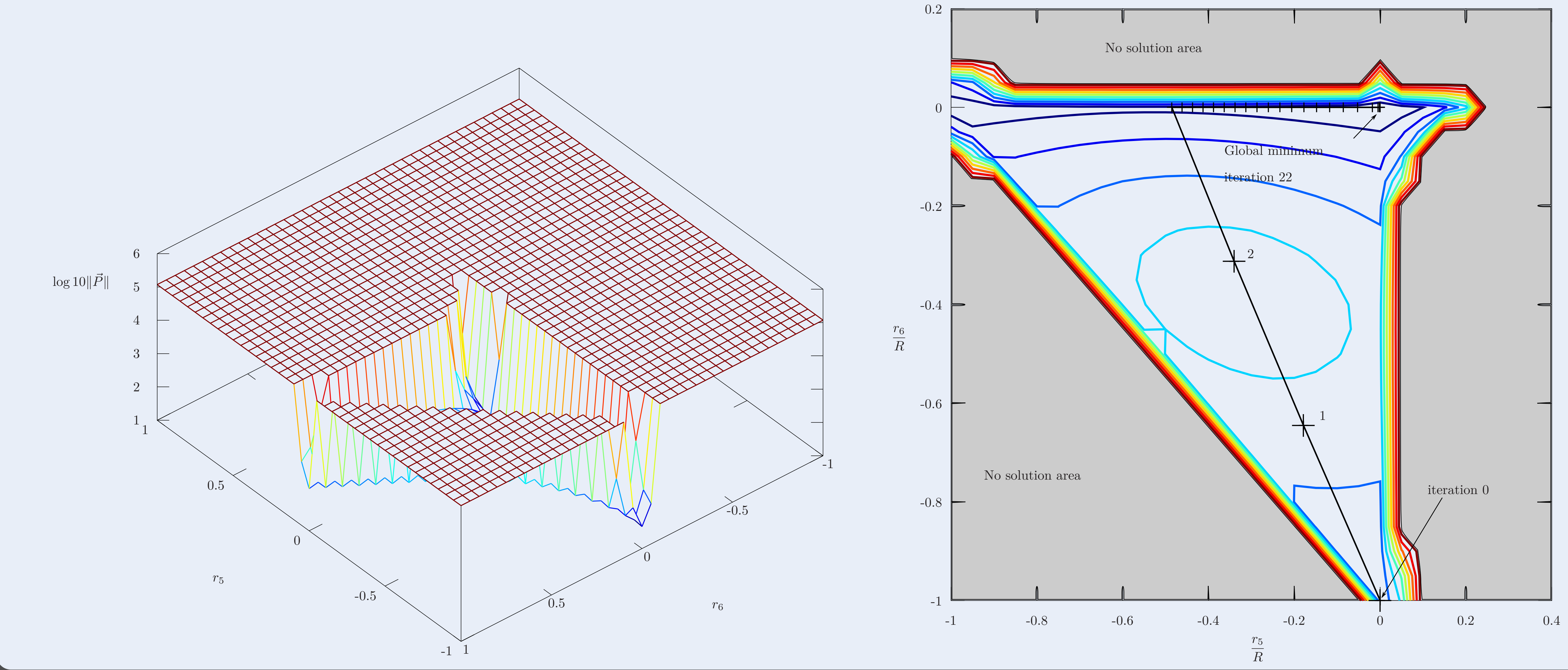

\section{Optimization algorithm}

We propose to solve this non-convex optimization problem using successive convex optimization. Let $\mathbf{U}=\operatorname{diag}\left(\mathbf{A}\left(\mathbf{R}^{\zeta}\right)\right)$ and $\mathbf{V}\left(\mathbf{R}^{\zeta}\right)=\mathbf{U}-\mathbf{A}\left(\mathbf{R}^{\zeta}\right)$ then optimization criterion becomes:

$$
\begin{aligned}
& \text { U. } \underbrace{\mathbf{P}}_{\text {Variable }}-\mathbf{V}\left(\mathbf{R}^{\zeta}\right) \cdot \underbrace{\mathbf{P}_{c s t}}_{\text {Constant }}=\mathbf{B}\left(\mathbf{R}^{\zeta}\right) \\
& \hat{\mathbf{P}}=\mathbf{U}^{-1}\left(\mathbf{B}\left(\mathbf{R}^{\zeta}\right)+\mathbf{V}\left(\mathbf{R}^{\zeta}\right) \cdot \mathbf{P}_{c s t}\right)
\end{aligned}
$$

We showed the minimisation of $\hat{\mathbf{P}}$ as a fonction of $\mathbf{R}_{c T}^{\mathcal{E}}$ is a strictly convex optimisation problem.

Algorithm 1. 1. Choose an admissible $\mathbf{R}^{\zeta}[i$ (initialisation on direct transmission point, always a solution)

2. Solving problem on that point $\mathbf{P}[i]=\mathbf{A}\left(\mathbf{R}^{\mathcal{E}}[i]\right)^{-1} \cdot \mathbf{B}\left(\mathbf{R}^{\mathcal{E}}[i]\right)$.

3. We minimise power with fixed interference. $\hat{\mathbf{P}}[i+1]=\mathbf{U}^{-1} \cdot\left(\mathbf{V}\left(\mathbf{R}^{\mathcal{E}}[i]\right) \cdot \mathbf{P}[i]+\mathbf{B}\left(\mathbf{R}^{\mathcal{E}}[i]\right)\right)$ $\mathbf{R}^{\mathcal{E}}[i+1]=\arg \left(\min _{\mathbf{R}^{\varepsilon} \in \mathbb{R}^{l-N-1}},\|\hat{\mathbf{P}}[i+1]\|_{1}\right)$

\section{References}

[1] L.O. Chua. Computer-aided analysis of electronic circuits. Prentice-Hall Series in Electrical and Computer Engineering, Englewood Cliffs: Prentice-Hall, 1975.

2] M. Johansson, L. Xiao, and Stephen Boyd. Simultaneous routing and power allocation in CDMA wireless data networks. In IEEE International Conference on Communications, volume 1, pages 51-55. IEEE, 2003.

[3] D. Julian and Stephen Boyd. Seeking foschini's genie: optimal rates and powers in wireless networks. 2004.

[4] L. Xiao, M. Johansson, and Stephen Boyd. Simultaneous routing and resource allocation via dual decomposition. Communications, IEEE Transactions on, 52(7):1136-1144, May 2004. 